\title{
COMPORTAMENTO DE BUSCA DE INFORMAÇÃO DOS ESTUDANTES DE GRADUAÇÃ̉O: CONTRIBUIÇÃO PARA A PESQUISA CIENTÍFICA NA UNIVERSIDADE EDUARDO MONDLANE DE MOÇAMBIQUE
}

\author{
COMPORTAMIENTO DE BÚSQUEDA DE INFORMACIÓN \\ DE LOS ESTUDIANTES DEL GRADO: CONTRIBUCIÓN \\ PARA LA INVESTIGACIÓN CIENTÍFICA EN LA \\ UNIVERSIDAD EDUARDO MONDLANE DE MOZAMBIQUE
}

\author{
Ilídio Lobato Ernesto Manhique* \\ Aida Varela Varela**
}

\begin{abstract}
RESUMO
Introdução: A pesquisa apresenta os resultados da dissertação de Mestrado em Ciência da Informação versando sobre o comportamento informacional, uma temática recorrente nas pesquisas da área, sobretudo, com o advento do que se convencionou chamar sociedade da informação.

Objetivo: Identificar e analisar os canais de informação utilizados pelos estudantes de graduação da Universidade Eduardo Mondlane de Moçambique (UEM), incluindo os fatores que influenciam a busca e avaliação da informação para a satisfação das necessidades ligadas à pesquisa científica.

Metodologia: Pesquisa de caráter descritivo, cuja coleta de dados foi através da aplicação de questionários aos estudantes, que alguma vez tivessem participado do programa de formação de usuários da Biblioteca Central da UEM.

Resultados: Demonstram que os estudantes não adotam estratégias sistemáticas e precisas de busca de informação, optando por ações impulsivas que não seguem um planejamento claro e objetivo.

Conclusões: Apesar do discurso sobre o papel transformador das tecnologias, os estudantes utilizam a biblioteca tradicional como principal recurso de informação durante o processo de pesquisa científica.
\end{abstract}

\footnotetext{
* Mestre em Ciência da Informação pela Universidade Federal da Bahia (UFBA). Professor na Escola Superior de Jornalismo de Moçambique E-mail: ilidiolobato@gmail.com

** Doutora em Ciência da Informação pela Universidade de Brasília (UNB). Professora do programa de Pós-graduação em Ciência da Informação da Universidade Federal da Bahia (UFBA). E-mail: varela1946@hotmail.com
}

Inf. Inf., Londrina, v. 21, n. 1, p. 283 - 305, jan./abr. 2016.

http:www.uel.br/revistas/informacao/ 
Palavras-chave: Comportamento informacional. Estudantes. Necessidades informacionais.

\section{INTRODUÇÃO}

A escolha do tema deste estudo se deveu às vivências profissionais, nas quais se pôde observar situações envolvendo estudantes de graduação em práticas informacionais desenvolvidas em bibliotecas universitárias e em outros centros de informação e investigação. Apesar da densidade de pesquisas relacionadas à temática no panorama internacional, no contexto específico de Moçambique não há evidência de estudos tratando de comportamento e competências de busca e uso da informação. As pesquisas existentes focalizam o papel transformador das tecnologias de informação para desenvolvimento econômico, no âmbito dos programas de inclusão digital, com foco nas ferramentas tecnológicas, no que Warschauer (2003) designa de primeiro nível de inclusão digital. Esse foco encontra respaldo na Política de Informática e sua respectiva estratégia de implementação, um documento governamental publicado no ano 2000, contendo as diretrizes com as quais o governo de Moçambique pretendia a sua inserção na sociedade da informação. Porém, esse documento privilegiando 0 aporte tecnológico, negligenciou outras dimensões sociais e humanas de uso e apropriação dessas ferramentas para a construção do conhecimento.

Perante a lacuna observada, este estudo pretende analisar o comportamento informacional dos estudantes de graduação da Universidade Eduardo Mondlane de Moçambique, perante situações de busca de informação para a pesquisa científica, incluindo os fatores que influenciam a escolha de determinados de canais e recursos de informação. Optou-se pelos estudantes da educação superior, porque é nesta fase em que desenvolvem as habilidades de leitura, autonomia de 
busca e uso da informação, incluindo a mobilização do pensamento reflexivo para atribuir significados à informação.

Para fundamentar o arcabouço teórico sobre a evolução históricoconceitual do termo comportamento informacional foram adotados estudos desenvolvidos por: Dervin e Nilan (1986); Kuhlthau (1991, 2008); Wilson (1999, 2000); Pettigrew, Fidel e Bruce (2001); Capurro (2007) e outros. A investigação do problema foi realizada a partir de uma pesquisa descritiva, onde foram aplicados questionários junto a 40 estudantes de graduação e a análise privilegiou as abordagens qualiquanti.

Os resultados do estudo mostraram que apesar da retórica discursiva ligada à massificação do uso das tecnologias de informação, os estudantes reportaram que utilizam a biblioteca como principal recurso de informação para satisfazer suas necessidades ligadas à pesquisa científica. A conclusão indica a necessidade das bibliotecas universitárias, em colaboração com os professores, desenvolverem programas de formação de usuários no sentido de potencializar a atitude científica dos estudantes.

\section{COMPORTAMENTO INFORMACIONAL: ASPECTOS CONCEITUAIS}

No campo da Ciência da Informação, o estudo do comportamento informacional é descrito como evolução dos estudos de usuários ou necessidades e usos de informação, uma área tradicional da Biblioteconomia e Ciência da Informação, largamente difundida a partir da década de 1970. De acordo com Wilson (1999), os estudos modernos do comportamento informacional têm a sua origem na Royal Scientific Information Conference de 1948, momento marcado pela apresentação de um número considerável de artigos sobre esta temática. Entretanto, vale ressaltar que não se empregava o termo comportamento informacional e, geralmente, tratava do uso de 
documentos e da biblioteca. Porém, o mesmo autor reconhece que estes estudos já vinham sendo realizados desde os princípios do século XX e tratavam do uso da biblioteca, enfatizando questões ligadas a classes sociais da sua clientela e, em geral, tinham pouca preocupação com as necessidades que levavam as pessoas a usar biblioteca como fonte de informação (WILSON, 1999).

Vários autores buscam explicar o conceito de comportamento informacional ou necessidades e usos da informação, entretanto, as suas abordagens tendem a ser limitantes, na medida em que se baseiam numa visão unidimensional, seja comportamentalista, cognitiva ou social. As discussões nesta área incidem também sobre a aplicabilidade semântica do termo comportamento informacional para referir-se aos processos de busca e uso da informação. Pettigrew, Fidel e Bruce (2001) sustentam que alguns autores sugerem que o termo comportamento informacional é inadequado, porque pode ser associado, de forma equivocada, ao paradigma behaviorista da psicologia e, assim, não considerar outros aspectos contextuais de interesse nas pesquisas do comportamento informacional. Outros, ainda, sugerem que o uso do termo comportamento informacional é, gramaticamente, incorreto porque a informação não tem comportamento.

Foi no meio desta controvérsia que o termo ganhou uma aceitação generalizada e tem sido amplamente usado por vários autores em várias pesquisas. Thomas Wilson, um dos autores que contribuiu para a popularização do termo, define comportamento informacional como:

[...] a totalidade do comportamento humano em relação às fontes e canais de informação de informação, incluindo a busca passiva e ativa da informação e o uso da informação. Assim, inclui a comunicação face a face com os outros, assim como a recepção passiva de informação [...] sem intenção de agir sobre a informação dada (WILSON, 2000). 
Por sua vez, Pettigrew, Fidel e Bruce (2001, p. 44) definem comportamento informacional como "[...] o estudo de como as pessoas necessitam, buscam e atribuem significado à informação em diferentes contextos, incluindo o local de trabalho e na vida cotidiana." Portanto, os autores buscam o explicar as nuances do comportamento informacional com base numa perspectiva multifacetada que inclui todos os aspectos contextuais do processo de busca e uso da informação. Para Ingwersen (1996) e Dervin e Nilan (1986) o desenvolvimento de uma necessidade de informação é resultado do processo de comunicação, sensoriamento e pensamento humano. O resultado de tal fenômeno é uma situação que faz o estado cognitivo do indivíduo reconhecer uma insuficiência ou incompletude de conhecimento.

No seu estudo sobre modelos de comportamento informacional, Wilson (1999) aponta vários problemas que as primeiras abordagens modernas sobre necessidade e usos da informação trouxeram para a construção de uma teoria sobre a área. A primeira é a tradição positivista e os métodos de pesquisa quantitativos que eram inadequados para o estudo do comportamento humano: muitas coisas eram contadas em função do número de visitas feitas a uma biblioteca, do número de inscrições a uma revista ou em função do número de itens citados (WILSON, 1999). A visão que norteou esses estudos de necessidades e usos da informação foi caracterizada por Dervin e Nilan (1986) em torno de sete elementos:

1. A informação objetiva

2. Tendência mecanicista e passiva dos usuários de informação

3. A trans-situacionalidade,

4. A visão atomística

5. Comportamento externo da informação

6. A individualidade caótica

7. Pesquisa quantitativa. 
Esta percepção revelou-se pouco suficiente para 0 desenvolvimento de uma teoria ou mesmo a prática deste campo. Esta visão reflete as tendências teóricas que dominaram a Ciência da Informação na fase inicial do seu surgimento, com particular destaque para a teoria matemática da comunicação de Shannon e Weaver (1948), que definem a informação (mensagem) como algo independente à intervenção mental dos sujeitos. Para os autores:

[...] o problema fundamental da comunicação é o de reproduzir exata ou aproximadamente uma mensagem a partir de um ponto para o outro. Frequentemente, a mensagem tem um significado, mas estes aspectos semânticos são irrelevantes para os problemas de engenharia. $O$ aspecto significante é que a atual mensagem foi selecionada a partir de um conjunto de mensagens possíveis [...] e o sistema deve ser concebido para operar para cada seleção possível (SHANNON; WEAVER, 1948, p. 5).

Como se pode depreender, os estudos iniciados a partir da segunda metade do século XX estão preocupados, não com os aspectos humanos do uso da informação, mas com 0 fator determinístico do uso das fontes e sistemas de informação, isto é, uma abordagem centrada no sistema. O paradigma que dominou estes estudos, o behaviorista, se sustenta na crença de que a metodologia usada para analisar o comportamento humano deveria dar ênfase à objetividade e neutralidade (GASQUE; COSTA, 2010, p. 26). Segundo as autoras, uma das limitações deste modelo científico operacional refletia uma preocupação positivista, tendência natural das pesquisas até então nas Ciências Sociais.

Por isso, Capurro (2007) enquadra esse primeiro período da Ciência da Informação ao paradigma físico, baseado na teoria de recuperação da informação (information retriavel). A essência deste paradigma postula que há algo, um objeto físico, que um emissor transmite a um receptor que, curiosamente, 
[...] Shannon não designa este objeto como informação, mas como mensagens, ou mais precisamente como signos que deveriam ser, em princípio, reconhecidos univocamente pelo receptor mediante certas condições ideias como são a utilização desses signos pelo emissor e pelo receptor, a ausencia de fontes que perturbam a transmissão (noise sources) (CAPURRO, 2007, p.17).

Esta teoria, tomada como modelo da Ciência da Informação, implica uma analogia entre o transporte físico de um sinal e a transmissão de uma mensagem, cujos aspectos semânticos são descartados por Shannon. Assim, de acordo com esta teoria, o que reduz a incerteza não é a informação propriamente dita, mas sim a mensagem. É evidente que no campo da Ciência da Informação, o que este paradigma exclui é o papel ativo do sujeito cogniscente (usuário) no processo de recuperação da informação científica em particular, assim como de todo o processo informativo e comunicativo (CAPURRO, 2007).

Nesta concepção, a biblioteca aparece como suporte ao ensino/pesquisa e proporciona o acesso físico à informação organizada. $O$ profissional da informação assume o papel de intermediário da informação. O paradigma informacional e educacional reproduzido é o tradicional, apesar do aporte tecnológico (DUDZIAK, 2003).

Foram, portanto, os limites dessa teoria que levaram à emergência de um paradigma oposto, o cognitivo (CAPURRO, 2007) ou alternativo (DERVIN; NILAN, 1986). Entretanto, isso não significa um processo histórico e epistemológico linear, pois para uma Ciência da Informação unificada e não, meramente, reducionista, é necessário observar as relações análogas, equivocas e unívocas entre os diversos conceitos de informação e as suas respectivas teorias e campos de aplicação (CAPURRO, 2007). Essas relações ficaram conhecidas como Trilema de Capurro (FLEISSNER; HOFKIRCHNER, 1995 apud CAPURRO, 2007). 


\subsection{Abordagem Cognitiva ou Alternativa de Busca de Informação}

No final da década de 1970, vários autores se preocuparam em conceber uma abordagem alternativa sobre os elementos fundamentais das pesquisas sobre necessidades da informação, notadamente, a redefinição do conceito, a natureza do uso da informação, a utilidade das diferentes abordagens para o estudo do comportamento humano e as consequências dos diferentes modelos empíricos e teóricos do comportamento informacional. Ocorre, neste período, a mudança de ênfase nos estudos sobre as necessidades e usos da informação, de uma abordagem centrada no sistema de informação, para uma abordagem centrada no usuário. Nesta perspectiva nomes como Dervin, Kuhlthau e Wilson, são regularmente associados a estas mudanças, reconhecendo que as necessidades de informação ocorrem tanto no campo cognitivo, quer no campo sociológico.

As pesquisas embasadas no paradigma tradicional são constantemente criticadas em razão da falta de uma teoria coerente e resultados substanciais produzidos. No entanto, de acordo com Ingwersen (1996) a perspectiva centrada no usuário ou paradigma cognitivo, como refere Ellis, demonstra, também, os mesmos problemas de fragmentação e construção teórica $A d$ Hoc. De acordo com o autor, na abordagem centrada no usuário a informação é entendida como resultado da interpretação humana durante a interação com as fontes ou sistemas de informação através de qualquer forma de mediação ou interface. No entanto, apesar do enfoque cognitivista da sua abordagem, a autor acrescente a perspectiva social afirmando que "[...] o processo de busca de informação concentra-se além do indivíduo, pois inclui, também, o impacto social de domínio científico nos processos comportamentais." (INGWERSEN, 1996, p. 12). Por isso, Capurro (2007) considera que Ingwersen se encontra em posição intermédia entre o paradigma cognitivo mentalista de Brookes e o paradigma social. 
A abordagem de Ingwersen tem como suporte os elementos da teoria dos Estados Anômalos do Conhecimento (Annomalous States of Knowledge - ASK) desenvolvida por Nicholas Belkin. Esta teoria parte da premissa de que a necessidade e busca da informação emerge a partir de uma anomalia reconhecida no estado do conhecimento do usuário sobre determinado tópico ou situação, e, no geral, os conhecimentos ao alcance do individuo não são suficientes para resolver os problemas (BELKIN; ODDY; BROOKS, 1982). Essa situação inicial é também denominada "situação problemática" (WERSIG, 1979 apud CAPURRO, 2007) e teve um impacto significativo no estudo e desenho de sistemas de recuperação da informação.

A partir da abordagem que resultou na criação do modelo sensemaking, Dervin e Nilan (1986) também apontam a necessidade de desenvolvimento de abordagens cognitivas para questões de necessidade e uso da informação. A visão cognitiva é definida pelos autores como um conjunto de construtos para o entendimento do comportamento informacional que se concentra, fundamentalmente, nos atributos do individuo para responder as necessidades de informação. Esta visão caracteriza-se por conceber a informação como algo subjetivo, pelo construtivismo e o papel ativo dos usuários, pela valorização da situacionalidade, por apresentar uma visão holística da experiência humana, pelo cognitivismo, pela individualidade sistemática e pela pesquisa qualitativa.

A visão alternativa do comportamento informacional encara a informação como algo construído pelos indivíduos e se concentra nas formas como as pessoas constroem sentidos. Focaliza o entendimento do uso da informação em situações particulares e preocupa-se com a interação entre os usuários e os sistemas. (DERVIN; NILAN, 1986).

Reportando-se às pesquisas deste período, Figueiredo (1994 apud BAPTISTA; CUNHA, 2007) refere-se à prevalência do "princípio de menor esforço" na busca de informação, onde a facilidade de acesso 
determina o uso da informação pelos usuários. Entre os estudos empíricos recentes que suportam com evidência o "princípio de menor esforço", destaca-se o de Gasque (2011) sobre o comportamento de busca de informação de estudantes de pós-graduação, em que a internet aparece como principal recurso de informação mais utilizado devido à facilidade de acesso e às questões de custo-benefício.

Embora vários autores se tenham identificado com a perspectiva cognitiva, desenvolveu-se, nos finais da década de 1980, a abordagem social que tem sido usada por vários autores da Ciência da Informação, entre eles Capurro (2007), Wersig e Neveling (1975) que enfatizam o caráter e a responsabilidade social desta área do conhecimento, preenchendo as necessidades de informação justificáveis individual e socialmente. Capurro (2007) assinala que o paradigma que social emerge dos limites do paradigma cognitivo, que considera, exclusivamente, o usuário cognoscente, deixando de lado os condicionalismos sociais e materiais que vinculam a existência do ser humano.

No âmbito da busca da informação, esta visão tem como foco o contexto social em que emergem as necessidades de informação. Contrariamente à abordagem behaviorista que tendia a objetivar 0 contexto, "[...] descrevendo-o como uma entidade separada do objeto de estudo, a abordagem social trata o contexto de forma interpretativa e holística e considera-o como portador do significado" (TALJA et al. apud PETTIGREW; FIDEL; BRUCE, 2001, p. 54). Nesse sentido, a abordagem social foi desenvolvida para tratar dos fenômenos do comportamento informacional que se dão fora do âmbito cognitivo. Concentrando-se nos aspectos sociais, os pesquisadores buscam entender o impacto das relações interpessoais e dinâmicas sobre o fluxo informacional e sobre como a partilha da informação é parte integrante da comunicação humana (PETTIGREW; FIDEL; BRUCE, 2001, p. 54). 
Considerando a natureza complexa do comportamento informacional humano, vários autores enfatizam a necessidade de abarcar múltiplos pontos de vistas para a compreensão deste fenômeno. Segundo Petegrew; Fidel e Bruce (2001) o modelo baseado numa única visão analítica, seja cognitivista ou social, não é suficientemente forte para descrever, analisar, explicar ou prever este fenômeno multifacetado.

Nestes termos, o profissional de informação assume um papel educacional importante para tornar mais profundo e efetivo o processo de busca de informação. Tal função educacional se efetiva através da mediação que, de acordo com Almeida Júnior (2009), constitui uma ação indispensável para apropriação do conhecimento e, inclusive, aponta esta noção como objeto da Ciência da Informação em detrimento da informação. Para o autor a mediação faz parte do discurso e toda a prática dos profissionais de informação e "[...] é um processo sociocultural que resulta da relação entre os sujeitos com o mundo." (ALMEIDA JÚNIOR, 2009, p. 93). O autor refuta a ideia de imparcialidade e neutralidade do profissional da informação, por isso, introduz a noção de interferência para demonstrar o seu papel ativo em todo o processo informacional. Esta visão encontra respaldo nas teorias da psicologia cognitiva, sobretudo o construtivismo, que concebem o conhecimento como construção do individuo em interação permanente com o meio sociocultural.

A noção de interferência constitui a chave no Processo de Busca de Informação (ISP), modelo concebido por Kuhlthau (1991) cujo aspecto central é o principio da incerteza. Segundo este modelo, o axioma de que a informação reduz a incerteza não é necessariamente aplicável na experiência do usuário no processo de busca de informação, pois em algumas situações nova informação aumenta a incerteza. Isto ajuda-nos a desmistificar a ideia de que o aumento da incerteza nos primeiros estágios de busca da informação é sintoma de 
que algo está errado. Pelo contrário, a incerteza na perspectiva do usuário é uma experiência natural no processo de busca (KUHLTHAU, 2008). Segundo a autora o aumento da incerteza cria uma zona de intervenção para os mediadores ou intermediários que apoiam os usuários no processo de busca significados a partir da informação. Baseado no modelo ISP e no principio de incerteza, Kuhlthau (2008) desenvolveu o conceito de zona de intervenção, que se apoia na ideia de que o aumento da incerteza determina a necessidade de assistência. Zona de intervenção é um conceito modelado a partir da Zona de Desenvolvimento Proximal de Vygotsky (1978) que dá o caminho para o entendimento da intervenção no processo construtivista de uma pessoa. Para a Kuhlthau (2008) a zona de intervenção é a área em que o usuário da informação faz com assistência de outra pessoa o que não pode fazer sozinho. A intervenção nesta zona permite aos indivíduos o cumprimento das suas tarefas. Entretanto, a intervenção fora desta zona é desnecessária e ineficiente e é encarada pelos usuários como intrusiva.

Esta acepção mostra que a interferência é um processo regrado que se efetua de acordo com as necessidades e características dos usuários de informação, valorando os seus aspectos sociais e culturais. A função dos bibliotecários nos processos de busca e uso da informação insere-se no que Davallon (2003) designa de mediação pedagógica, em que a assume a posição de formador. Esta mediação implica uma regulação das interações educativas, para que a relação aprendizsaberes seja efetiva e conduza a uma aprendizagem.

\section{PROCEDIMENTOS METODOLÓGICOS}

A metodologia é o aspecto central da pesquisa que determina, em certo grau, a cientificidade do conhecimento produzido e reproduzido dentro e fora do campo científico. Suas atividades caminham sempre em duas direções: numa elabora teorias, métodos, princípios e estabelece 
resultados. Noutra, inventa, ratifica seu caminho, abandona certas vias e orienta-se para novas rotas, assumindo o caráter provisório peculiar do conhecimento científico (MINAYO, 2010)

O trabalho realizado caracterizou-se como um estudo de caso, em nível descritivo, envolvendo estudantes de graduação da UEM, em que buscou analisar o comportamento de busca de informação para satisfazer necessidades de pesquisa científica, incluindo os fatores que influenciam o uso de determinados canais de informação. As abordagens qualitativa e quantitativa (quali-quanti) nortearam construção desta pesquisa, pois fornecem uma perspectiva de interação metodológica necessária para a análise de dados empíricos. A combinação de métodos (quali-quanti) deve ser concebida a partir do entendimento epistemológico de que nos fenômenos sociais há possibilidades de se analisarem regularidades, frequências, mas também relações representações pontos de vista e lógica interna dos sujeitos em ação (MINAYO, 2010). Para a autora, "[...] o uso de métodos quantitativos tem por objetivo trazer à luz dados, indicadores e tendências observáveis ou produzir modelos teóricos de alta abstração com aplicabilidade prática." (MINAYO, 2010, p. 56). Neste estudo a abordagem quantitativa permitiu operacionalizar dois objetivos da pesquisa. O primeiro, ligado à identificação dos principais canais de informação utilizados pelos pesquisadores, incluindo seu a análise do seu perfil.

A abordagem qualitativa será usada para a análise das variáveis que influenciam comportamento de busca de informação dos estudantes da UEM. A abordagem qualitativa permite trabalhar com o universo de significados, motivações, aspirações, crenças, valores e atitudes, o que corresponde a um espaço mais profundo das relações, dos processos e dos fenômenos que não podem ser reduzidos à operacionalização de variáveis e caracteriza-se pela empiria e pela sistematização progressiva do conhecimento até a compreensão da lógica interna do 
grupo ou do processo estudado (MINAYO, 2010). Além de permitir desvelar processos sociais ainda pouco conhecidos referentes a grupos particulares, este método propicia a construção de novas abordagens, revisão e criação de novos conceitos e categorias durante a pesquisa (MINAYO, 2010, p. 57).

A coleta de dados foi baseada na aplicação de questionários junto a 40 estudantes de graduação de diversos cursos da UEM. Esta técnica apresenta inúmeras vantagens, entre as quais, a possibilidade de atingir um grande número de indivíduos, mesmo que estejam dispersas numa área geográfica e, pelo fato de não expor os pesquisados à influência das opiniões.

A amostra foi constituída por estudantes do quarto semestre que tivessem participado do processo de formação de usuários na Biblioteca Central da Universidade Eduardo Mondlane. A escolha deste universo se deveu ao fato de ter sido o primeiro grupo de estudantes a participar da formação nos moldes atuais em 2010 e, desde a formação, terem passado por experiências de pesquisas que exigissem a conhecimentos de busca, avaliação e uso da informação.

\section{RESULTADOS E DISCUSSÃO}

O processo de pesquisa científica envolve várias etapas interrelacionadas, sendo que uma das mais importantes consiste na exploração das fontes e recursos de informação disponíveis. A exploração é uma das fases do modelo ISP de Carol Kuhlthau (1991) caracterizada pelo aumento da incerteza decorrente da quantidade de informação encontrada. Em relação aos principais recursos de informação mais utilizados, os estudantes reportaram a biblioteca como principal canal de informação conforme atesta a tabela que se segue: 
Ilídio Lobato Ernesto Manhique, Aida Varela Varela

Comportamento de busca de informação dos estudantes de graduação:

contribuição para a pesquisa científica na Universidade Eduardo Mondlane de Moçambique

Tabela 1 - Principais Recursos de Informação Utilizados pelos Estudantes

\begin{tabular}{c|c|c}
\hline Recursos de informação & $\mathbf{N}$ & $(\%)$ \\
\hline Biblioteca & 24 & 60 \\
\hline Internet & 11 & 27.5 \\
\hline Colegas & 4 & 10 \\
\hline Outro & 1 & 2.5 \\
\hline Total & 40 & 100 \\
\hline
\end{tabular}

Fonte: Dados da pesquisa

Apesar de o contexto atual ser dominado pelas tecnologias de informação que possibilitam o acesso remoto da informação em vários canais, suportes e formatos, a tabela 1 sugere que a biblioteca física da universidade continua sendo o principal recurso solicitado pelos estudantes da UEM para satisfazer suas necessidades de informação em situações de pesquisa científica. Esse fato contraria as versões mais otimistas do progresso tecnológico, entre as quais de Lancaster (1996) que preconizava uma sociedade sem papel (paperless society) e outros o fim das bibliotecas tradicionais. Pelo contrário, os resultados da pesquisa mostram a adaptabilidade das bibliotecas aos diversos paradigmas tecnológicos em decorrência da sua permeabilidade às mudanças. A sua sobrevivência está ancorada à apropriação tecnológica, sem desvirtuar a sua missão e concepção tradicional, o que resultou na criação de bibliotecas híbridas, que fornecem materiais impressos e digitais.

Resultado diferente foi encontrado na pesquisa de Gasque (2011) sobre o comportamento informacional dos estudantes de pós-graduação no Brasil, em que mais de metade dos sujeitos da sua pesquisa, apontarem a internet como principal recurso de informação, argumentando que a opção dos estudantes pode estar relacionada a questões de custo-benefício devido às facilidades de acesso à informação e baixo custo.

As questões de custo-benefício carecem de problematização para o contexto de Moçambique, devido à deficiente rede doméstica de acesso à internet no país, o que dificulta o uso e exploração efetiva das 
Ilídio Lobato Ernesto Manhique, Aida Varela Varela

Comportamento de busca de informação dos estudantes de graduação:

contribuição para a pesquisa científica na Universidade Eduardo Mondlane de Moçambique

possibilidades informacionais disponíveis na rede. Esta constatação corrobora a visão de Warschauer (2003) sobre a exclusão digital prevalecente, sobretudo nos países do terceiro mundo, entre os quais Moçambique faz parte.

Outra constatação da pesquisa reside no desconhecimento dos mecanismos de filtragem da informação disponível na internet, o que se pode associar à preferência dos estudantes pela biblioteca física da universidade. Os estudantes apontaram algumas desvantagens da internet como fonte de informação para a pesquisa científica:

Quadro 1- Problemas de Uso da Internet na Pesquisa Científica

1. Informação não credível

2. Informação sem valor científico

3. Informação produzida e disponibilizada sem nenhum critério de avaliação prévia

4. Poucos artigos disponíveis para download grátis

5. Pouca informação científica sobre Moçambique

Fonte: Dados da pesquisa

Os dados disponíveis do quadro acima indiciam dois tipos de barreiras: a) a barreira econômica, ligada às dificuldades de acesso à produção científica que não seja de acesso livre, podendo resultar no que Kuramoto (2005) designa de exclusão cognitiva e, b) barreiras cognitivas ligadas à competência de informacional, pois se observa a dificuldade dos estudantes em discernir a cientificidade da informação disponível na rede. Apenas um quarto dos participantes indicou que na internet apenas buscam informação em canais oficiais de publicação e disseminação do conhecimento, porque tal conhecimento é legitimado pelas comunidades científicas através da avaliação por pares.

Esta constatação mostra a necessidade de mediação por parte dos professores e profissionais da informação para tornar efetiva a utilização dos recursos pelos estudantes. Por isso, corroboramos da visão de Kuhlthau que se refere à necessidade de intervir sobre os 
Ilídio Lobato Ernesto Manhique, Aida Varela Varela

Comportamento de busca de informação dos estudantes de graduação:

contribuição para a pesquisa científica na Universidade Eduardo Mondlane de Moçambique

usuários nos primeiros estágios do processo de busca de informação visando reduzir sua incerteza.

A busca e uso da informação se inserem no tópico geral do comportamento informacional e reflete a necessidade de compreender os fenômenos na perspectiva multidimensional, como processos naturais do ser humano ser aprendiz da própria vida. Buscar e usar a informação de forma eficiente requer a sistematização de competências específicas. No que concerne à busca da informação, tais competências demandam monitoração de estratégias, o conhecimento e definição de canais ou fontes de informação, competências para usar tecnologias de informação e a avaliação do processo (GASQUE, 2011, p. 23).

Os dados da pesquisa trazem como evidência o fraco domínio das ferramentas tecnológicas existentes nas bibliotecas, tais como catálogos eletrônicos, assim como a busca de informação em bases de dados, conforme atesta a tabela 2 :

Tabela 2 - Conhecimentos de Busca de Informação em Bases de Dados

\begin{tabular}{l|c|c}
\multicolumn{1}{c|}{ Opção } & N & (\%) \\
\hline Sei acessar & 8 & 20 \\
\hline Só acesso com auxílio dos bibliotecários e/ou colegas & 25 & 62.5 \\
\hline Não sei & 7 & 17.5 \\
\hline Total & $\mathbf{4 0}$ & $\mathbf{1 0 0}$ \\
\hline
\end{tabular}

Fonte: Dados da pesquisa

Os resultados mostram que, apesar da formação de usuários desenvolvida pela Biblioteca Central da Universidade Eduardo Mondlane, os estudantes não alcançaram, ainda, o nível de autonomia necessária para a aprendizagem permanente e efetiva. Mais de metade dos participantes considera que só consegue efetuar a busca de informação em bases de dados com assistência dos profissionais de informação ou com auxílio de outras pessoas familiarizadas com essas ferramentas. Essa tendência encontra respaldo na visão construtivista de Kuhlthau $(1991,2008)$ que moldou, a partir dos trabalhos de 
Ilídio Lobato Ernesto Manhique, Aida Varela Varela

Comportamento de busca de informação dos estudantes de graduação:

contribuição para a pesquisa científica na Universidade Eduardo Mondlane de Moçambique

Vygotsky, o conceito de Zona de Intervenção, que se refere à necessidade de mediação dos profissionais de informação nos primeiros estágios de busca da informação.

Esta constatação interfere diretamente nos critérios e fatores que influenciam a escolha dos canais e fontes de informação para satisfazer suas necessidades de informação no âmbito da pesquisa científica. De acordo com Kuhlthau (1991) a seleção é um dos momentos da pesquisa que exige sentido crítico dos estudantes para a obtenção de informação relevante para a efetivação da pesquisa. Esse processo pode ser influenciado por vários fatores, entre os quais o reconhecimento da autoridade do pesquisador, a familiaridade com o tema, a avaliação pela coerência de abordagem. Nessa componente, os resultados foram sistematizados na seguinte tabela:

Tabela 3 - Critérios de Seleção da Informação Utilizados pelos Estudantes

\begin{tabular}{l|c}
\hline \multicolumn{1}{c|}{ Critério } & Resultado \\
\hline Quando é constantemente citado na área & 10 \\
\hline Apenas relacionado com o tema da pesquisa & 5 \\
\hline Quando se refere a um teórico da área & 9 \\
\hline Referências fornecidas pelo professor & 14 \\
\hline Coerência de abordagem & 2 \\
\hline
\end{tabular}

Fonte: Dados da pesquisa

A tabela mostra que os estudantes empregam critérios diferenciados para a seleção da informação durante o processo de pesquisa científica, podendo resultar das diferenças disciplinares dos sujeitos que compõe o universo da pesquisa. No entanto, a pesquisa evidenciou que grande parte dos participantes assumem como critério principal de seleção de informação as referências fornecidas pelo professor. A dependência excessiva pelo professor pode tornar pernicioso o processo de aprendizagem independente, porque raramente se mobiliza o pensamento reflexivo, base fundamental da competência informacional e aprendizagem permanente, conforme 
indica maioria dos trabalhos revisados sobre o processo construtivista de aprendizagem. Porém, esse fenômeno pode se associar à prevalência do paradigma educacional tradicional, em que o professor é a figura central da do processo de "transmissão" do conhecimento.

O segundo critério de seleção do material diz respeito ao mapeamento das citações. Quer dizer, os estudantes têm a tendência de avaliar positivamente os autores regularmente referenciados na área. Este critério já demonstra certa maturidade, pois a seleção é antecedida de um processo de pesquisa, interpretação, ponderação e crítica. No entanto, apenas $5 \%$ dos participantes usam a coerência de abordagem para selecionar o material, o que demonstra a opção por critérios de avaliação objetiva e não subjetiva.

No geral, os estudantes têm pouco conhecimento das fontes de informação e, muitas vezes, as buscas não obedecem nenhum planejamento e é resultado de uma ação impulsiva;

\section{CONSIDERAÇÕES FINAIS}

Os resultados obtidos nesta pesquisa indicam que, apesar, de toda a discussão em relação às tecnologias de informação como facilitadoras do acesso à informação para o processo de construção do conhecimento, estas ferramentas continuam sendo subutilizadas pelos estudantes da UEM. Os estudantes desta universidade utilizam a biblioteca como principal canal e recurso de informação, decorrente de vários fatores, tais como as barreiras econômicas, que dificultam o acesso à rede doméstica de internet, devido aos custos elevados, e as barreiras cognitivas, ligadas ao desconhecimento dos mecanismos de filtragem da informação na condução das buscas em meios eletrônicos. A pesquisa evidenciou que a avaliação e seleção da informação não obedecem a critérios precisos e sistemáticos, que pudessem satisfazer, efetivamente, as suas necessidades da informação. 
Desse modo, torna-se importante que as bibliotecas da universidade ampliem sua função educacional e de centros de promoção da aprendizagem permanente, através de atividades de formação de usuários que potencializam a atitude científica dos estudantes. Nessa base, os profissionais de informação assumiriam a função mediadora do processo de busca e uso da informação perante situações de pesquisa científica.

\section{REFERÊNCIAS}

ALMEIDA JÚNIOR, Oswaldo Francisco de. Mediação da informação e múltiplas linguagens. Tendências da Pesquisa Brasileira em Ciência da Informação, Brasília, v.2, n.1, p.89-103, jan./dez. 2009.

BAPTISTA, Sofia Galvão; CUNHA, Murilo Bastos da. Estudo de usuários: visão global dos métodos de coleta de dados. Perspectiva em Ciências da Informação, Belo Horizonte, v.12, n. 2, p.168-185, 2007.

BELKIN, Nicholas J.; ODDY, Robert N.; BROOKS, Helen M. ASK for information retrieval. The Journal of Documentation, London, v. 38, n. 2, p.61-71, jun. 1982.

CAPURRO, Rafael. Epistemología y ciencia de la información. Enlace, Maracaibo, v. 4, n. 1, p. 11-29, 2007.

DAVALLON, Jean. La médiation: la communication en procès?

Médiations \& Médiateurs, v. 19, 2003.

DERVIN, Brenda; NILAN, Michael. Information needs and uses. Annual Review of Information Science and Technology, New York, v. 21, p. 3-33, 1986.

DUDZIAK, Elisabeth Adriana. Information literacy: princípios, filosofia e prática. Ciência da Informação, Brasília, v. 32, n. 1, p. 23-35, jan./abr. 2003.

GASQUE, Kelley Cristine Gonçalves Dias. Pesquisas na pós-graduação: o uso do pensamento reflexivo no letramento informacional. Ciência da Informação, Brasília, v. 40 n. 1, p. 22-37, jan./abr. 2011 
GASQUE, Kelley Cristine Gonçalves Dias; COSTA, Sely Maria de Souza. Evolução teórico-metodológica dos estudos de comportamento informacional dos usuários. Ciência da Informação, Brasília, v. 39, n. 1, p. 21-32, jan./abr. 2010. Disponível em: <http://www.scielo.br/pdf/ci/v39n1/v39n1a02.pdf>. Acesso em: 15 out. 2012.

INGWERSEN, Peter. Cognitive perspectives of information retrieval. Journal of Documentation, London, v. 52, n. 1, p. 3-50, 1996.

KUHLTHAU, Carol C. Inside the search process: information seeking from the user's perspective. Journal of the American Society for Information Science, New York, v. 42, n. 5, p. 361-371, 1991.

KUHLTHAU, Carol C. From Information to meaning: confronting challenges of theTwenty-fi rst century. Libri, Trujillo, v. 58, p. 66-73, 2008 .

LANCASTER, F. W. Avaliação de serviços de bibliotecas. Tradução António Agenor Briquet de Lemos. Brasília: Briquet de Lemos, 1996.

MINAYO, Maria Cecília de Souza. O desafio do conhecimento: pesquisa qualitativa em saúde. 7. ed. São Paulo: HUCITEC; Rio de Janeiro: ABRASCO. 2010.

MOÇAMBIQUE. Resolução n. 28/2000, de 12 de dezembro de 2000. Aprova a política de informática. Boletim da República [de Moçambique], Maputo, n. 49, $1^{\text {a }}$ S., $3^{\circ}$ Supl.

PETTIGREW, Karen E.; FIDEL, Raya; BRUCE, Harry. Conceptual frameworks in information behavior. Annual Review of Information Science and Technology, New York, v. 35, p. 43-78, 2001.

SHANNON, Claude; WEAVER, Warren. The mathematical theory of communication. Urbana: University of Illinois Press, 1949.

VYGOTSKY, Lev S. Interaction between learning and development. In: p. 79-91. Mind and society. Cambridge: Harvard University Press, 1978.

WARSCHAUER, Mark. Tecnology and social inclusion: rethinking the digital divide. Cambridge: The MIT Press, 2003.

WERSIG, Gernot; NEVELING, U. The phenomena of interest to Information Science. Information Scientist, London, v.9, n.4, p.127140, 1975. 
WILSON, Thomas D. Models in information behaviour research. Journal of Documentation, London, v.55, n.3, p. 249-270, June 1999.

WILSON, Thomas D. Human information behaviour. Informing Science, Santa Rosa, v. 3, n. 2, p. 49-56, 2000.

\title{
Title
}

Information searching behavoir of graduate students: contribution for scientific Research in Eduardo Mondlane University of Mozambque.

\begin{abstract}
Introduction: This research presents the results of dissertation of master in Information Science, approaching about information behavior, one of the recurring theme in the field, especially with the advent of what is called information society.

Objective: It sought to identify and to analyze the main channels used by undergraduate students of Eduardo Mondlane University of Mozambique (UEM), including the factors that influence the searching and evaluation of information to satisfy needs related to scientific research.

Methodology: The study was regarded as descriptive and the procedure of data collecting was through the questionnaire to undergraduate students who has participated in the program of users' education of Central Library of UEM.

Results: The results demonstrate that students do not adopt systematic and accurate information search strategies, opting to impulsive actions that do not follow a clear plan.

Conclusions: Despite the discourse on the changing role of technology, students use the traditional library as the main resource of information.
\end{abstract}

Keywords: Information behavior. Students. Information needs.

\section{Titulo}

Comportamiento de búsqueda de información de los estudiantes del grado: Contribución para la investigación científica en la Universidad Eduardo Mondlane de Mozambique

\section{Resumen}

Introducción: La investigación presenta los resultados de la tesis de Maestría en Ciencias de la Información sobre el comportamiento de la información, un tema recurrente en las investigaciones del área, especialmente con el adviento de la llamada sociedad de la información.

Objetivo: Identificar y analizar los canales de información utilizados por los estudiantes del grado de la Universidad Eduardo Mondlane de Mozambique (UEM), incluidos los factores que influyen en la búsqueda y evaluación de la 
Ilídio Lobato Ernesto Manhique, Aida Varela Varela

Comportamento de busca de informação dos estudantes de graduação:

contribuição para a pesquisa científica na Universidade Eduardo Mondlane de Moçambique

información para satisfacer las necesidades relacionadas con la investigación científica.

Metodología: Encuesta de carácter descriptivo, cuya recolección de datos fue a través de la aplicación de cuestionarios a los estudiantes que habían participado en el programa de formación de los usuarios de la Biblioteca Central de la UEM.

Resultados: Muestran que los estudiantes no adoptan estrategias sistemáticas y precisas de búsqueda de información, optando por acciones impulsivas que no siguen una planificación clara y objetiva.

Conclusiones: A pesar del discurso sobre el papel transformador de la tecnología, los estudiantes usan la biblioteca tradicional como el principal recurso de información durante el proceso de investigación científica.

Palabras clave: Comportamiento de la información. Información. Estudiantes. Necesidades informativas.

Recebido em: 23.07.2014

Aceito em: 07.03.2016

Inf. Inf., Londrina, v. 21, n. 1, p. $283-305$, jan./abr. 2016. 